\title{
Notas sobre el proceso de implementación de la agenda para la reforma urbana en Brasil
}

Edésio Fernandes DPU Associates (Development Planning Unit of University College London); Teaching Faculty of the Lincoln Institute of Land Policy.

RESUMEN | Este artículo describe el proceso de reforma urbana en Brasil desde la perspectiva de las innovaciones legales e institucionales verificadas en el país a partir de la promulgación de la Constitución Federal de 1988, las cuales incluyen el Estatuto de la Ciudad de 2001 y la creación del Ministerio de las Ciudades y del Consejo Nacional de las Ciudades en 2003. El artículo analiza los avances producidos hasta la fecha y las cuestiones pendientes en materia de reforma urbana. En este marco, nota la necesidad de una combinación de reforma jurídica, cambio institucional y movilización social renovada en todos los niveles, para aprovechar los nuevos espacios políticos creados por el proceso de reforma urbana y así revertir la exclusión socioespacial que ha caracterizado el desarrollo urbano en Brasil durante las últimas décadas.

PALABRAS ClAVE | Política urbana, gestión urbana, integración social.

ABSTRACT | This paper describes the process of urban reform in Brazil from the perspective of the legal and institutional innovations that have taken place in the country since the promulgation of the 1988 Federal Constitution, including the 2001 City Statute and the creation of both the Ministry of Cities and the National Council of Cities in 2003. The paper analyses the progress made so far and the pending questions regarding the promotion of urban reform. From this perspective, the paper stresses the need for the combination of legal reform, institutional change and renewed social mobilization at all levels so as to make the most of the new political spaces created by the urban reform process, thus reversing the process of sociospatial exclusion that has characterized urban development in Brazil over the last decades.

KEY WORDS | Urban policy, urban management, social integration.

Recibido el 22 de septiembre de 2008, aprobado el 1 de mayo de 2010.

Correspondencia: 1 Hereford Mansions, Hereford Road, Londres W2 5BA, Reino Unido.

E-mail: edesiofernandes@compsuerve.com 


\section{Introducción}

Desde finales de la década de los ochenta se ha promovido en Brasil un importante proceso de reforma urbana, en forma lenta pero continua. Desde la promulgación del capítulo pionero sobre política urbana en la Constitución Federal de 1988 se introdujeron cambios legales e institucionales significativos en el plano nacional, creando así un orden jurídico-urbanístico completamente nuevo que fue consolidado con la promulgación del Estatuto de la Ciudad de 2001 y la instalación, en 2003, tanto del Ministerio de las Ciudades como del Consejo Nacional de las Ciudades. Más recientemente, inversiones récord por parte el gobierno federal en vivienda, saneamiento, infraestructura y otros programas sociales han planteado una nueva serie de cuestiones para los responsables por las políticas públicas en el país.

A semejanza de la mayoría de los países de ingresos bajos, medios y en transición, Brasil se encuentra en la incómoda posición de tener que "cambiar las ruedas con el automóvil en movimiento", dados los graves problemas sociales, urbanos y ambientales que se han acumulado a lo largo de décadas de urbanización rápida y negligencia gubernamental; lo mismo como resultado del patrón de la acción gubernamental en ese período. Esta tarea se ha complicado aún más por los efectos de los cambios más recientes en la naturaleza y la dinámica del proceso de urbanización en la economía global. Más que nunca, la importancia de definir los marcos reguladores e institucionales más adecuados no puede ser subestimada. La promoción de la reforma urbana lleva tiempo, y requiere continuidad y respuestas sistemáticas en todos los niveles de gobierno, para atender a la escala de los problemas existentes. La reforma urbana también requiere de otros factores fundamentales, como la generación de mayores capacidades de acción de los gobiernos -especialmente en la esfera local-, la aprobación de políticas articuladas de acuerdo con una agenda claramente definida y la asignación de los recursos financieros necesarios.

Aun reconociendo los avances, todavía falta recorrer un largo camino en Brasil y existen muchos obstáculos importantes que superar para que los efectos de la reforma jurídica e institucional se manifiesten de manera más clara.

Este artículo describe los aspectos principales del proceso de reforma urbana en Brasil, con base en la literatura ya consolidada en el país, así como, en gran medida, en mi propia experiencia profesional y en mi producción académica. Luego de un breve resumen del contexto histórico, el artículo discutirá el nuevo orden jurídico-urbanístico creado en Brasil a partir de la promulgación de la Constitución Federal de 1988; se pondrá especial énfasis en las disposiciones del Estatuto de la Ciudad de 2001, que reglamenta el capítulo constitucional. El artículo describirá entonces el nuevo aparato institucional resultante de la creación del Ministerio de las Ciudades y del Consejo Nacional de las Ciudades en 2003, y también tratará algunos de los problemas principales que afectan a estas nuevas instituciones. Como conclusión, se argumentará que, si bien se han logrado progresos significativos hacia la concreción de la agenda para la reforma urbana en Brasil, la 
renovación de la movilización social en todos los niveles gubernamentales es crucial para la consolidación y la expansión de este tan reclamado proceso del nuevo orden jurídico-urbanístico.

Sobre todo, la experiencia brasileña muestra que la reforma urbana requiere de una combinación precisa y a menudo esquiva de movilización social renovada, reforma jurídica y cambio institucional. Este es un proceso abierto, cuya calidad política descansa en última instancia en la capacidad de la sociedad brasileña para hacer valer en forma eficaz su derecho legal a estar presente y participar activamente en el proceso de toma de decisiones del orden urbanístico. Las reglas del juego han sido ya alteradas en forma significativa desde la promulgación de la Constitución Federal de 1988; lo que queda por verse es si los espacios políticos recientemente creados podrán o no ser usados en forma tal que consigan avances en la agenda de la reforma urbana en el país.

\section{Antecedentes}

Brasil ha experimentado uno de los procesos de reorganización socioeconómica y territorial más drásticos del mundo como resultado de su urbanización rápida a partir de la década del treinta. El 83 por ciento de la población total vive en zonas urbanas y existe una altísima concentración de población y actividades económicas en una porción muy pequeña del territorio nacional. Todas las estadísticas relevantes y los datos disponibles indican claramente la compleja naturaleza de este proceso, que ha sido ampliamente discutido (Fernandes y Valença, 2001). En breve, la rápida urbanización en Brasil ha generado una crisis urbana nacional caracterizada por una combinación de segregación socioespacial, impactos ambientales, violencia y desarrollo informal. El creciente déficit habitacional se ha estimado entre 7,6 y 6,4 millones de unidades, y unos 15 millones de familias adicionales viven en condiciones inadecuadas.

Sin embargo, a pesar de la tradición de larga data de centralización política, legal y financiera durante la mayor parte del proceso de urbanización, hasta hace poco el gobierno federal no había sido capaz de formular e implementar políticas nacionales urbanas y territoriales amplias y articuladas, ni siquiera de crear una infraestructura institucional básica para atender a los muchos problemas que afectan a las ciudades y a la creciente población urbana. De hecho, antes de la creación del Ministerio de las Ciudades en 2003, la falta de una respuesta gubernamental adecuada en el nivel federal -dada la naturaleza elitista y exclusivista de la actual intervención gubernamental a través de los escasos programas y políticas existentes- fue uno de los factores principales en la determinación de la naturaleza exclusivista del desarrollo territorial y urbano en Brasil. Esto empeoró más aún debido a condiciones de exclusión política que fueron resultado del sistema jurídico vigente hasta la promulgación de la Constitución Federal de 1988. Este sistema no sólo socavaba los poderes político-legales de los gobiernos municipales, sino también la calidad del sistema democrático representativo en todos los niveles gubernamentales. 
Otro factor fundamental en la creación y reproducción de este proceso fue el orden jurídico prohibitivo y obsoleto que mantenía el anacrónico paradigma del Código Civil de 1916, reforzando así la tradición histórica de los derechos de propiedad privada sin salvedades (Fernandes, 2002a). Como resultado, hasta hace poco el alcance de la intervención estatal a través de la planificación territorial urbana era muy limitado, en particular en el nivel municipal. Si bien aún la mayor parte de los municipios sólo tiene un conjunto de leyes básicas -que determinan los perímetros urbanos y los tradicionales códigos de edificación-, recién a partir de mediados de la década de los sesenta una nueva generación de leyes de planificación más ambiciosas comenzó a ser puesta en vigencia en algunas de las ciudades principales, aunque inicialmente su legalidad fue frecuentemente cuestionada. Si bien es menos popular en Brasil que internacionalmente, el impresionante caso de Curitiba demuestra que muchos problemas con el orden legal pueden superarse exitosamente si se ha instaurado un sólido pacto político-institucional. De cualquier manera, Curitiba es de hecho la excepción que confirma la regla, debido a la naturaleza conservadora e incluso exclusivista de las estrategias de planificación urbana adoptadas en esa ciudad hasta hace poco (Fernandes, 1995a).

Desde mediados de la década de los setenta, y especialmente desde principios de la década de los ochenta, aparecieron resquebrajamientos importantes en el largamente establecido régimen militar, como resultado de una poderosa combinación de factores: la creciente movilización social a través de los sindicatos, las organizaciones civiles, los movimientos sociales, las asociaciones de residentes, los grupos vinculados a la rama progresista de la Iglesia Católica y otros canales colectivos; la reorganización de los partidos políticos tradicionales y la creación de otros nuevos que expresaban demandas políticas renovadas de cambio político-institucional, en particular a través de las elecciones democráticas y del fortalecimiento de los gobiernos locales y, además, en menor medida, la reconfiguración del capital terrateniente e inmobiliario. Los primeros intentos significativos para la democratización de la gestión urbana en el nivel municipal pueden identificarse a mediados de la década de los setenta (Kowarick, 1994).

Como resultado del creciente proceso de movilización social y cambio político, una importante ley federal fue aprobada en 1979, con el objeto de regular la subdivisión/loteamiento de la tierra urbana en el plano nacional y proporcionar elementos básicos para la regularización de los asentamientos informales consolidados en las ciudades. Poco tiempo después, varias leyes ambientales progresistas fueron puestas en vigencia, incluso el pionero reconocimiento legal, en 1985, de una acción civil pública para defender intereses difusos en cuestiones ambientales, con la extensión del locus standi a las nacientes ONG (Fernandes, 1995b; 1994). En el nivel municipal, los primeros programas de regularización de asentamientos informales fueron formulados en 1983 en Belo Horizonte y Recife (Fernandes, 1993).

Un Movimiento Nacional de Reforma Urbana surgió entonces e involucró a varios de los movimientos sociales, sindicatos y organizaciones académicas existentes en ese momento y comenzó a ganar fuerza dentro del proceso más amplio de aper- 
tura política destinado a promover la redemocratización del país (de Souza, 2001). Con el creciente fortalecimiento de un nuevo pacto sociopolítico, hubo un amplio reconocimiento de la necesidad de profundizar los cambios legales y políticos en el país, lo que condujo al notable -aunque en muchos aspectos defectuoso- proceso de redacción de la Constitución Federal entre 1986 y 1988.

\section{La Constitución Federal de 1988}

El proceso de urbanización en Brasil comenzó en la década de los treinta y tuvo su punto culminante en la década de los setenta, durante la cual muchas constituciones federales fueron promulgadas: las de 1934, 1937, 1946, 1967 y la enmienda general no. 1 de 1969. Sin embargo, hasta la entrada en vigencia de la Constitución Federal de 1988 no existieron disposiciones constitucionales específicas para guiar los procesos de desarrollo territorial y gestión urbana. Fue el capítulo original sobre política urbana introducido por la Constitución de 1988 que fijó la base políticojurídica para la promoción de la reforma urbana en Brasil.

De hecho, desde que el proceso mismo de preparación de la Constitución recibió un nivel de participación popular sin precedentes, gran parte de este capítulo constitucional fue desarrollado según la Enmienda Popular sobre Política Urbana, que había sido formulada, discutida, difundida y firmada por más de 130.000 organizaciones sociales e individuos involucrados en el Movimiento Nacional de Reforma Urbana. Esta enmienda proponía el reconocimiento de los siguientes principios generales:

- autonomía del gobierno municipal;

- gestión democrática de las ciudades;

- el derecho social a la vivienda;

- el derecho a la regularización de los asentamientos informales consolidados;

- la función social de la propiedad urbana, y

- la necesidad de combatir la especulación sobre la tierra y las edificaciones en zonas urbanas.

Otra importante enmienda popular propuso la aprobación de una serie de disposiciones constitucionales que reconocían el derecho colectivo a un ambiente equilibrado (Fernandes, 1992a; 1996).

Luego de un proceso de intensa disputa en el Congreso Constituyente, un capítulo progresista sobre la conservación ambiental fue finalmente aprobado, junto con un capítulo pionero -aunque limitado- sobre política urbana (Fernandes y Rolnik, 1998; Fernandes, 1995c).

La mayoría de estos reclamos populares fueron en alguna medida reconocidos. El derecho a la regularización de los asentamientos informales consolidados fue promovido mediante la aprobación de nuevos instrumentos jurídicos tendientes 
a viabilizar esos programas, en relación con los asentamientos formados sobre tierras privadas (derechos de usucapión, esto es, derechos de prescripción adquisitiva o posesión adversa en cinco años) y sobre la tierra pública ("concesión del derecho real al uso", una forma de arrendamiento). La necesidad de combatir la especulación sobre la tierra y las edificaciones en las ciudades fue tratada en forma explícita y se crearon nuevos instrumentos jurídicos para este propósito: obligación de subdivisión, utilización y edificación; tributación progresiva sobre la propiedad, y una forma punitoria de expropiación. El principio de la gestión democrática de ciudades fue completamente respaldado cuando la Constitución de 1988 proporcionó una serie de instrumentos político-jurídicos tendientes a ampliar las condiciones de participación directa en todo el proceso de toma de decisiones.

La autonomía del gobierno municipal también fue reconocida en términos legales, políticos y, en menor medida, también financieros, de tal manera que el federalismo brasileño es considerado uno de los más descentralizados en todo el mundo, y los municipios brasileños son comparados con los cantones suizos en términos de autonomía política. Sin embargo, lamentablemente la Constitución de 1988 no adoptó una postura correcta sobre la cuestión fundamental de la administración metropolitana, y transfirió ese poder a los estados federales (Fernandes, 1992b).

En ese momento no se logró el consenso político para el reconocimiento del derecho social a la vivienda. Respecto del reconocimiento del principio de la función social de la propiedad urbana, existieron acalorados debates entre grupos antagónicos, de los que resultó la siguiente fórmula: la propiedad privada se reconoce como un derecho fundamental siempre que cumpla funciones sociales, que son aquellas determinadas por los planes directores municipales y otras leyes urbanísticas y ambientales. Al condicionar el principio de la función social de la propiedad urbana a la aprobación de las leyes municipales de planificación, la intención de los grupos conservadores parecía ser la de convertir a este principio en mera retórica. La limitada experiencia brasileña en planificación urbana hasta el momento había sido en gran medida ineficaz en términos de su capacidad de revertir las condiciones exclusivistas del desarrollo urbano. Por el contrario, el desarrollo informal de la tierra -que ha ganado una dimensión aún mayor a partir de la década de los setenta- ha resultado en gran medida de la naturaleza elitista y tecnocrática de la planificación urbana. Enfrentado a la imposibilidad de aprobar otra fórmula constitucional más progresista, el Movimiento Nacional de Reforma Urbana decidió entonces aprovechar al máximo la situación y subvertir la disposición aprobada, proponiendo una inversión consciente en la formulación de planes directores municipales en todo el país, que fueran tanto incluyentes como participativos.

\section{Un nuevo orden jurídico-urbanístico en la década de los noventa}

Un orden urbano-legal completamente nuevo fue inaugurado con la promulgación de la Constitución Federal de 1988, que llevó a una serie de experiencias locales progresistas durante toda la década de los noventa. Muchos municipios aproba- 
ron nuevas leyes urbanísticas y ambientales, incluidos algunos planes directores, y Brasil se convirtió en un interesante laboratorio para la planificación y la gestión urbanas, con nuevas estrategias y procesos que establecían nuevas relaciones entre los sectores estatal, comunitario, privado y voluntario en cuestiones relativas al desarrollo territorial urbano. Se formularon nuevos programas de regularización de asentamientos informales, que comenzaron a ser implementados en muchos municipios (Fernandes, 2000; 2002b).

Se puso particular énfasis en la calidad política de todos esos procesos y se fomentó la participación popular en diversas áreas, desde la definición de políticas urbanas en "conferencias de ciudades" hasta la introducción de nuevos procesos de presupuesto participativo (de Souza, 2001; Fernandes, 1995d). Desde entonces, los municipios como Porto Alegre, Santo André, Diadema, Recife y Belo Horizonte han sido reconocidos internacionalmente por sus estrategias de gestión urbana y compromiso con la agenda de la reforma urbana. Sin embargo, la falta de regulación del capítulo sobre política urbana en la Constitución de 1988 a través de legislación federal -como es tradición en Brasil-, derivó en una serie de dificultades político-jurídicas que fueron fomentadas por grupos enfrentados al progreso del nuevo orden jurídico-urbanístico. Esto debilitó la amplitud y el alcance de las prometedoras experiencias locales. Como resultado, las organizaciones involucradas en el Movimiento Nacional de Reforma Urbana decidieron consolidarse y ampliarse inicialmente mediante la creación del Foro Nacional para la Reforma Urbana (FNRU), a principios de la década de los noventa.

Conformado por un amplio conjunto de organizaciones y movimientos nacionales y locales, el FNRU es colectivamente coordinado actualmente por varias organizaciones, siendo las principales FASE -Federación de Organizaciones para el Bienestar Social y Educativo; CONAM -Confederación Nacional de Asociaciones de Residentes; CMP -Centro de Movimientos Populares; MNLM -Movimiento Nacional para la Lucha por la Vivienda; UNMP -Unión Nacional de Movimientos Populares; COHRE Américas -Centro por el Derecho a la Vivienda sin Desalojos; FNA -Federación Nacional de Arquitectos y Planificadores Urbanos, etc. El FNRU sigue jugando un papel decisivo, enarbolando el estandarte de la reforma urbana y promoviendo su agenda en el plano nacional. Tres de sus objetivos principales en la década de los noventa fueron la incorporación del derecho social a la vivienda en la Constitución Federal de 1988, la aprobación de una ley federal para regular el capítulo constitucional, y la aprobación de un proyecto de ley, originado a partir de una iniciativa popular aprovechando las nuevas posibilidades creadas por la Constitución de 1988, que propuso la creación de un Fondo Nacional para la Vivienda Social -FNHIS. Al mismo tiempo, el FNRU también solicitó la creación por parte del gobierno federal de un aparato institucional en el nivel nacional que promoviese la planificación y políticas urbanas en Brasil.

Un largo proceso de movilización social y de feroz lucha política se mantuvo a lo largo de la década de los noventa y en el nuevo siglo, dentro y fuera del Congreso Nacional. En 1999, una nueva ley federal reguló el accionar de las "organizaciones 
de interés público de la sociedad civil”, para permitirles recibir fondos públicos. El derecho social a la vivienda fue finalmente aprobado por una enmienda constitucional en 2000, y la ley federal para la creación del FNHIS fue finalmente puesta en vigencia en 2005. Resultó de especial importancia la promulgación en 2001 del internacionalmente elogiado Estatuto de la Ciudad, la ley federal sobre política urbana.

\section{El Estatuto de la Ciudad de 2001}

El pionero Estatuto de la Ciudad de 2001 reguló y amplió las disposiciones constitucionales antes mencionadas, y reconoció en forma explícita el "derecho a la ciudad” en Brasil (Fernandes, 2003). Fue el resultado de un intenso proceso de negociación que duró más de 10 años, dentro y más allá del Congreso Nacional, y confirmó y amplió la función político-jurídica fundamental de los municipios en la formulación de los lineamientos para la planificación urbana, así como para la conducción de los procesos de desarrollo y gestión urbanos.

El Estatuto de la Ciudad rompió con la tradición de larga data del derecho civil, y sentó las bases del nuevo paradigma político-jurídico para el uso de la tierra urbana y el control del desarrollo territorial. Lo logró particularmente mediante el refuerzo de la disposición constitucional que reconocía el poder y la obligación de los gobiernos municipales de controlar el proceso de desarrollo urbano mediante la formulación de políticas territoriales y de uso del suelo en que los intereses individuales de los propietarios coexistan necesariamente con otros intereses sociales, culturales y ambientales, de otros grupos y de la ciudad en su conjunto. El Estatuto de la Ciudad avanzó sobre el principio de las "funciones sociales de la propiedad y de la ciudad", reemplazando así al paradigma individualista del Código Civil de 1916.

Además, el Estatuto aportó diversos instrumentos legales, urbanos y fiscales que las administraciones municipales pudieran usar, especialmente en el contexto de sus planes directores, para regular, inducir o revertir los mercados de tierra urbana e inmuebles de acuerdo a criterios de inclusión social y sostenibilidad ambiental. Todos esos instrumentos pueden, y deben, usarse en forma combinada, atendiendo no sólo a regular el proceso de uso y desarrollo territorial, sino en especial a inducirlo, de acuerdo a un "concepto de ciudad" que será expresado mediante los planes directores municipales. Con la nueva ley, se brindaron más condiciones a los municipios para interferir con, y posiblemente revertir en alguna medida, el patrón y la dinámica de los mercados formales e informales de tierra urbana, en especial aquellos de naturaleza especulativa, que desde hace mucho tiempo han introducido la exclusión social y la segregación espacial en Brasil.

De hecho, la combinación de los mecanismos tradicionales de planificación -zonificación, subdivisión, regulaciones edilicias, etc.- con los nuevos instrumentos -subdivisión obligatoria, órdenes de construcción y uso, uso extrafiscal de los impuestos locales sobre la propiedad progresivamente a lo largo del tiempo, sanción-expropiación con pago en títulos de deuda pública, derechos de superficie, derechos preferenciales para el municipio, transferencia onerosa de los derechos 
de edificación, etc.- abrieron un nuevo abanico de posibilidades para la construcción por parte de los municipios de un nuevo orden urbano que puede ser más eficiente en lo económico, más justo en lo político y más sensible al espectro completo de cuestiones sociales y ambientales existentes.

Más aún, el Estatuto de la Ciudad indicó diversos procesos para que los municipios integrasen la planificación urbana, la legislación y la gestión para democratizar el proceso de toma de decisiones local y así legitimizar un orden jurídico-urbanístico nuevo y con orientación social. Se reconocieron diversos mecanismos para garantizar la participación eficaz de los ciudadanos y las asociaciones en la planificación y la gestión urbanas: audiencias, consultas, creación de consejos, informes de impacto ambiental y sobre los vecindarios, iniciativa popular para la propuesta de leyes urbanas, litigios públicos y, sobre todo, las prácticas del proceso de presupuesto participativo. La nueva ley enfatizó la importancia de establecer nuevas relaciones entre el Estado y los sectores privados y comunitarios, en especial mediante asociaciones y "operaciones urbanas" de vinculación a ser fomentadas dentro de un marco político-jurídico y fiscal claramente definido.

Al reglamentar la Constitución Federal de 1988, la legislación de 2001 también mejoró el orden legal respecto de la regularización de los asentamientos informales consolidados en zonas urbanas públicas y privadas, permitiendo a los municipios promover programas de regularización de tenencia de la tierra y así democratizar las condiciones de acceso a la tierra y la vivienda. Además de regular las instituciones constitucionales de usucapiao y de concesión del derecho real al uso antes mencionado, la nueva ley avanzó un paso más y permitió el uso colectivo de esos instrumentos. Posteriormente, todavía en 2001, dada la activa movilización del FNRU, la Disposición Provisional no. 2220 fue firmada por el presidente. Esto reconoció, para quienes ocupaban las tierras públicas hasta esa fecha, los derechos individuales o colectivos (conocidos como derechos subjetivos) y el otorgamiento, bajo ciertas circunstancias, de la "concesión del uso especial con finalidad de vivienda”, otra forma de derechos de arrendamiento, que es en último término independiente de los deseos de las autoridades públicas (por lo tanto, esto no fue sólo provisto como prerrogativa de las autoridades públicas).

Todos los municipios con más de 20.000 habitantes, entre otras categorías, recibieron una fecha límite de cinco años para crear y aprobar sus planes directores.

El Estatuto de la Ciudad ha sido complementado por nuevas e importantes leyes federales aprobadas con posterioridad: las que regulan las asociaciones público-privadas (2004) y los consorcios intermunicipales (2005). Más recientemente, diversas leyes federales fueron aprobadas en 2008 y 2009 para facilitar la regularización por los municipios de asentamientos informales, especialmente los que están ubicados en tierras del gobierno federal. Hace más de ocho años, una amplia discusión sigue creciendo en todo el país sobre la revisión de la ley federal de 1979 que rige la subdivisión de la tierra urbana y la regularización de los asentamientos informales.

Un proceso significativo de cambio institucional, en el que la creación del Ministerio de las Ciudades en 2003 merece una mención especial, ha apoyado también este proceso gradual y fundamental de reforma jurídica. 


\section{El Ministerio de las Ciudades}

Tal vez, por los celebrados antecedentes académicos y políticos de Fernando Henrique Cardoso y sus estudios de gran influencia sobre la naturaleza de la "cuestión urbana" en Brasil, la falta de una política urbana nacional y del aparato institucional correspondiente durante su gobierno (1995-2002) fueran particularmente frustrantes. Existieron algunos programas aislados y sectoriales, dispersos entre varios ministerios, que se ocupaban de aspectos de la cuestión urbana más amplia, pero no existió una política urbana nacional que los articulase, especialmente debido a que la Secretaría Nacional de Política Urbana existente disponía de poderes insignificantes y de pocos recursos.

Sólo con la elección del Presidente Lula en 2003 se tomó una decisión para crear el Ministerio de las Ciudades. Es importante remarcar que el nuevo ministerio no se ha creado como una decisión ejecutiva del nuevo presidente, sino como su respuesta al reclamo social defendido durante largo tiempo por el FNRU y otras partes interesadas, y esto le otorga una forma de legitimidad especial en el Ministerio de las Ciudades.

El Ministerio está compuesto de una Secretaría Ejecutiva que preside a cuatro secretarías nacionales: vivienda, saneamiento ambiental, transporte público y movilidad y programas territoriales y urbanos. Entre otras tareas, la Secretaría Ejecutiva se ha concentrado en desarrollar la capacidad de los municipios para actuar, inicialmente a través de una campaña nacional para la elaboración de catastros municipales multipropósito. Las cuatro secretarías, además de formular programas nacionales en sus respectivos temas, se han involucrado en diversas negociaciones con el Congreso Nacional para promover mayores cambios en el marco regulatorio vigente, con un relativo grado de éxito hasta el momento.

Dos iniciativas importantes en curso, implementadas por la Secretaría de Programas Territoriales y Urbanos, merecen una mención especial: el Programa Nacional para la Asistencia a la Regularización Territorial Urbana Sostenible y la Campaña Nacional para los Planes Directores Municipales Participativos.

\section{a El Programa Nacional para la Asistencia a la Regularización Territorial Ur- bana Sostenible}

Iniciado en 2003 con lo que el entonces ministro llamó un "presupuesto virtual", el Programa Nacional para la Asistencia a la Regularización Territorial Urbana Sostenible ha crecido en cuanto a sus recursos e impacto, y su importancia y alcance fueron reconocidos en 2005 por una generosa subvención de la Alianza de las Ciudades (Fernandes, 2006). El programa combina estrategias de intervención, articulación y movilización -legales, financieras, de planificación urbana y políticas- para crear las condiciones básicas en que los municipios puedan actuar. Se han otorgado subvenciones a municipios, estados federales y ONGs para promover la formulación e implementación de programas de regularización y el reconocimiento jurídico de los derechos de prescripción adquisitiva. Se puso especial énfasis en la 
definición de los criterios para la regularización de los asentamientos que ocupan tierras federales, y cientos de miles de títulos de arrendamiento ya han sido otorgados a sus ocupantes o están en proceso de ser finalizados.

Se han formado asociaciones prometedoras con muchas partes interesadas, en particular ONGs y movimientos sociales, así como también instituciones que representan registros de tierras, jueces y fiscales del gobierno, además de la Comisión para el Desarrollo Urbano del Congreso Nacional y la academia. Se han distribuido "equipos" educativos, que incluyen manuales con procedimientos detallados paso a paso. Una red virtual envía mensajes diarios a más de 10.000 personas e instituciones en todo Brasil. Un proyecto de lo más innovador y exitoso fue la promoción en 2006 de un curso virtual sobre regularización de tierra urbana dirigido a aproximadamente 900 personas con variados antecedentes profesionales y cargos institucionales de todo Brasil. El curso, de tres meses de duración, cubrió un amplio espectro de cuestiones relacionadas con los programas de regularización territorial, tanto en zonas privadas como públicas. Los participantes incluyeron a funcionarios de los gobiernos locales, de la mayoría de los gobiernos estatales y de varios ministerios del gobierno federal; a funcionarios de los registros de tierras, abogados, jueces y fiscales del gobierno; planificadores urbanos; miembros de ONGs y asociaciones; residentes de favelas, subdivisiones de tierra irregulares y quilombos (áreas ocupadas por los descendientes de antiguos esclavos). El curso fue promovido también en 2008 y en 2009, de manera más articulada con la discusión sobre los planes directores municipales.

\section{b La Campaña Nacional para los Planes Directores Municipales Participativos}

Otra iniciativa importante ha sido la Campaña Nacional para los Planes Directores Municipales Participativos, que jugó un papel decisivo en el impulso a la discusión y movilización nacional en torno a este tema. La aprobación de los planes directores municipales es un requisito legal que afecta a aproximadamente 1.600 municipios brasileños (de un total de 5.550 municipios), y es la calidad política y técnica de este proceso que finalmente determinará la medida en que las posibilidades del nuevo orden jurídico-urbanístico propuesto por el Estatuto de la Ciudad podrán realizarse.

Para que esta enorme tarea pueda ser completada correctamente, hay una importantísima necesidad por parte de los municipios de recibir no sólo la generación de capacidades de acción y los recursos financieros, sino también la información técnica y las formulaciones conceptuales adecuadas. Se han distribuido ampliamente "equipos" educativos, se otorgaron subvenciones a los municipios y a los consultores registrados comprometidos con la agenda de la reforma urbana; se creó un "banco de experiencias", que organizó materiales de más de 700 experiencias en curso, y una red virtual distribuye experiencias e información; seminarios y todo tipo de reuniones se han fomentado a lo largo del territorio nacional, siempre en asociación con instituciones locales. Como resultado, más de 1.400 municipios ya aprobaron o están en proceso de aprobación de sus planes directores. La calidad 
política de esos procesos ha variado mucho, así como los contenidos técnicos de los planes, pero no se puede negar que se trata de un enorme avance en un país donde hasta hace muy poco solamente unos 200 municipios tenían un orden jurídicourbanístico un poco más desarrollado que la demarcación de perímetros.

\section{c Problemasy restricciones}

Se ha logrado ya un progreso significativo en la implementación de la agenda para la reforma urbana en el plano nacional, y el Ministerio de las Ciudades ha ganado cada vez más credibilidad institucional, legitimidad social e influencia política. Sin embargo, el Ministerio de las Ciudades todavía se enfrenta a muchos problemas graves, de los cuales el más inmediato es su precaria organización institucional, su pequeño equipo y sus limitados recursos presupuestarios.

Todavía existe un grave problema de fragmentación que debe ser superado en la forma en que las políticas urbanas interrelacionadas se formulan dentro del ministerio, y en su relación con otros ministerios. La ley fundamental para el saneamiento ambiental formulada por el ministerio se estancó por largo tiempo en el Congreso Nacional, dadas las tensiones políticas resultantes de la distribución propuesta de poderes legales en esta cuestión, y una versión sustancialmente modificada fue finalmente aprobada en diciembre de 2006. Con el debido respeto a la importancia del recientemente aprobado FNHIS, así como a las mejoras ya implementadas en los programas federales existentes a través de la Caixa Economica Federal, el hecho es que todavía no se ha formulado una nueva política nacional de vivienda, abarcativa y articulada. La inversión federal en ambas áreas, vivienda y saneamiento, ha aumentado significativamente desde 2003, rompiendo de hecho los máximos históricos, pero dada la negligencia gubernamental durante tanto tiempo vigente en estas cuestiones y la magnitud de la deuda social acumulada, el presupuesto total aún resulta limitado.

La creación del Ministerio de las Ciudades ha brindado, ciertamente, más visibilidad a las preocupaciones urbanas desatendidas desde hace tanto tiempo, pero con este reconocimiento también han surgido nuevas disputas, incluidas discusiones sobre el control del mismo Ministerio de las Ciudades. Con el creciente reconocimiento de las dimensiones políticas de las cuestiones urbanas, han surgido feroces luchas políticas derivadas del continuo realineamiento de la cuestionable coalición política que apoya al Presidente Lula. Como consecuencia, si bien los cuatro secretarios nacionales mantuvieron sus puestos, en 2005 el primer Ministro de las Ciudades y la Secretaria Ejecutiva, provenientes de un partido político de centroizquierda, fueron reemplazados por personas nominadas por un partido político conservador y populista, sin sintonía con los principios de la agenda para la reforma urbana. Al mismo tiempo, la Comisión del Congreso Nacional para el Desarrollo Urbano (insignificante por mucho tiempo) ha recibido mayor visibilidad e influencia políticas, y pocos de sus miembros están completamente comprometidos con la agenda de la reforma urbana. 
Dadas todas esas limitaciones, el Ministerio de las Ciudades ha invertido sistemáticamente en el establecimiento de asociaciones de todo tipo -dentro del gobierno federal- a través de las relaciones intergubernamentales, con el Congreso Nacional y el poder judicial, con el sector privado y con los movimientos sociales organizados, las ONGs y la academia. Una parte fundamental de este proceso ha sido la profunda vinculación entre el Ministerio de las Ciudades y el Consejo Nacional de las Ciudades.

\section{d El Consejo Nacional de las Ciudades}

Tal vez el aspecto más extraordinario del nuevo aparato político-institucional que está siendo creado actualmente en Brasil ha sido la instalación del Consejo Nacional de las Ciudades. En abril de 2003 el Presidente Lula solicitó una movilización nacional para discutir una lista de metas de políticas territoriales, urbanas y de vivienda mediante una serie de conferencias municipales, en las que los delegados serían elegidos para participar en conferencias estaduales y, finalmente, en la conferencia nacional planificada para octubre de 2003. Se esperaba que aproximadamente 300 de los 5.571 municipios existentes tuviesen el tiempo y las condiciones para organizar conferencias locales. Lo que en realidad sucedió fue que más de 3.000 municipios lo hicieron, así como la totalidad de los 27 estados federales. Más de 2.500 delegados discutieron las directivas iniciales de política nacional sobre desarrollo urbano, así como el rango de propuestas específicas sectoriales de políticas nacionales sobre vivienda, planificación, saneamiento y transporte. Todos votaron sobre la definición de la lista final de principios que deberían guiar la formulación de políticas nacionales del Ministerio de las Ciudades.

Más aún, una de las deliberaciones más importantes de la Primera Conferencia Nacional de las Ciudades fue la creación del Consejo Nacional de las Ciudades, en el que fueron elegidos representantes de todos los sectores de partes interesadas. El consejo está compuesto por 86 miembros, 49 en representación de segmentos de la sociedad civil (movimientos populares, sindicatos, ONGs, instituciones académicas y el sector empresarial) y 37 en representación de las administraciones federal, de los estados federales y municipales. Los miembros se eligen por un período de dos años, lo que garantiza ampliamente la participación ciudadana en las deliberaciones del consejo, y el Ministerio de las Ciudades está legalmente obligado a seguir y respetar esas deliberaciones.

La Segunda Conferencia Nacional de las Ciudades se realizó en diciembre de 2005, nuevamente como la culminación de un proceso de movilización nacional. Dos mil quinientos delegados y 410 observadores de todos los estados federales y de distintos segmentos sociales debatieron una política nacional de desarrollo urbano más articulada, con el objeto de generar ciudades "más justas, democráticas y sostenibles". La Tercera Conferencia Nacional de las Ciudades se realizó en noviembre de 2007, con los temas "Desarrollo urbano con participación popular y justicia social” y “Avanzando en la gestión democrática de las ciudades”, además de proponer un balance de las acciones y políticas ya desarrolladas como resultado de 
las dos conferencias anteriores. En esa ocasión, el Presidente Lula firmó la Disposición Provisional no. 387, garantizando el acceso de las asociaciones y cooperativas de vivienda al FNHIS. La Cuarta Conferencia nacional debe ser realizada a fines del mes de junio de 2010, tratando del tema "Avances, dificultades y desafíos en la implementación de la política de desarrollo urbano".

El Consejo Nacional de las Ciudades se ha reunido en varias ocasiones, y ha sido reconocido en forma gradual como un foro sociopolítico de gran importancia. Este reconocimiento es inequívoco entre las partes interesadas más directamente involucradas con las preocupaciones urbanas discutidas por el Consejo. Sin embargo, aún necesita de la aceptación total por parte del gobierno federal como un todo, en particular en lo que respecta a la aceptación completa de las deliberaciones del Consejo, así como para traducirlas en las disposiciones presupuestarias adecuadas. Es también fundamental que el Consejo sea fortalecido para controlar el propio Ministerio de las Ciudades, impidiendo que la agenda de la reforma urbana que ha justificado su creación sea reemplazada por un balcón de negocios clientelistas.

En este cuadro general se debe discutir, aunque brevemente, el impacto que el Plan de Aceleración del Crecimiento -PAC-, lanzado por el Presidente Lula en enero de 2007, puede tener para el avance de la reforma urbana y consolidación del aparato institucional federal. Un volumen nunca imaginado de recursos financieros -al inicio anunciado en más de quinientos mil millones de reales, pero repetidamente reducido en razón de "limitaciones" presupuestarias- ha sido destinado para inversiones en infraestructura, saneamiento, regularización de asentamientos informales y otras áreas, lo que ha despertado toda una nueva serie de cuestiones:

- ¿Existen proyectos adecuados para la aplicación de todos esos recursos?

- La administración pública, sobre todo en la esfera municipal, ¿tiene condiciones de gestionar esos proyectos y recursos de manera eficiente?

- ¿Existen procesos y canales adecuados de control social, fiscal y judicial para impedir la utilización clientelista de esos recursos, así como su desvío en prácticas de corrupción?

El mismo vale para el programa federal de vivienda de interés social, "Mi Casa, Mi Vida", lanzado por el Presidente Lula en 2009, prometiendo construir y distribuir 1.000 .000 casas en tres años, también involucrando inversiones récord del gobierno federal.

Es todavía temprano para hacer una evaluación consistente y justa del impacto del PAC y del programa de vivienda, pero ya son muchos los indicios preocupantes de que parte significativa de los recursos estaría siendo desperdiciada por falta de capacidad administrativa e eficiencia institucional, cuando no manipulada políticamente o, aun peor, desviada en prácticas de corrupción que ya enviaran a la cárcel a diversas personas, incluso empleados del Ministerio de las Ciudades en posiciones de gestión. 
De cualquier forma, la promoción de las conferencias nacionales y la acción del Ministerio de las Ciudades han marcado una diferencia en el rumbo de la política urbana en Brasil, y han conferido un nivel único de legitimidad sociopolítica al proceso de toma de decisiones. Por este motivo, ambas iniciativas recibieron el premio del Pergamino de Honor de UN-Hábitat, 2006.

\section{Conclusiones}

La aprobación del Estatuto de la Ciudad consolidó el orden constitucional en Brasil respecto del control del proceso de desarrollo urbano, con el objetivo de reorientar la acción estatal, los mercados de tierras e inmuebles y la sociedad en su conjunto de acuerdo a nuevos criterios legales, económicos, sociales y ambientales. Su materialización efectiva en políticas y programas dependerá de la reforma de los órdenes jurídico-urbanísticos locales, vale decir, del marco regulatorio e institucional general conformado en el nivel local para dirigir el uso del suelo y el desarrollo territorial por parte de los municipios, en particular a través de la aprobación de planes directores adecuados. El papel de los municipios es crucial para que el patrón exclusivista del desarrollo urbano en Brasil pueda ser revertido.

Si bien es innegable que el proceso de reforma urbana ha recibido un enorme impulso con las recientes reformas legales e institucionales, existen muchos problemas que deben ser superados y serios desafíos que deberán enfrentarse a nivel federal, por lo que las nuevas leyes e instituciones no pueden darse por hechas. El Estatuto de la Ciudad ha recibido gran cantidad de propuestas de cambios en el Congreso Nacional, muchas de las cuales, en caso de ser aprobadas, podrían socavar su potencial. Hasta ahora, la discusión de esos proyectos de ley está estancada en la Comisión de Desarrollo Urbano.

Más aún, la continuidad y la calidad de la acción del Ministerio de las Ciudades dependerán de cómo las disputas políticas existentes y los intereses contrapuestos se concilien. La existencia misma del ministerio ha sido cuestionada, en particular por personas que desearían fusionarlo con otros ministerios, dentro del contexto de un gobierno federal optimizado.

En un nivel más general, la realización completa de la agenda para la reforma urbana por parte del Ministerio de las Ciudades dependerá de cómo el gobierno federal en su conjunto entienda la centralidad de las cuestiones urbanas. En esta comprensión resulta crítica la promoción de una mayor integración interministerial y una articulación intergubernamental más fuerte. El Ministerio de las Ciudades requerirá también de una infraestructura institucional y una capacidad de acción más coherentes, además de los recursos necesarios para la promoción de la totalidad del nuevo conjunto de políticas y programas sociales. El control de desarrollo urbano no puede abandonarse a las fuerzas del mercado, pero tampoco puede dejarse sólo en manos de los gobiernos municipales. Existe una función primordial para el gobierno federal, así como para los gobiernos de los estados federales.

En un nivel más interno, el Ministerio de las Ciudades debe promover una mejor integración entre sus secretarías y programas respectivos. La aprobación de una politica 
de vivienda abarcativa destinada a los pobres es de enorme importancia, en parte para desacelerar el proceso del desarrollo informal. Atendiendo a este fin, la definición clara de una política nacional sobre la utilización de tierras e inmuebles federales es particularmente necesaria. La definición de una política de organización territorial articulada y un sistema de ciudades también es fundamental, incluido un tratamiento adecuado de la apremiante cuestión de la administración metropolitana. Debería ponerse más énfasis en los intentos de reconciliar las agendas ambientales "verde" y "marrón" en el país. Deben reforzarse las asociaciones existentes y formarse nuevas. La aplicación de los recursos del PAC y del programa "Mi Casa, Mi Vida" debe ser hecha de la manera más efectiva posible, para que esta oportunidad histórica de enfrentamiento de los problemas urbanos acumulados sea aprovechada al máximo.

Dicho esto, la experiencia brasileña ha demostrado claramente que, si la reforma urbana requiere la combinación del cambio institucional y la reforma jurídica, también depende en forma fundamental de la movilización social en todo el país. Este es de hecho un proceso altamente político, y la continua renovación de la movilización social en Brasil, a través del FNRU y de otros canales colectivos, dentro y fuera del aparato estatal, es la condición sine qua non del avance del movimiento para la reforma urbana en el país.

El proceso de reforma urbana es naturalmente una expresión de las condiciones históricas y de los procesos políticos brasileños, pero importantes lecciones pueden ser aprendidas por otros países y ciudades interesados en promover la inclusión social en las ciudades.

Además de los mencionados requerimientos sociopolíticos, institucionales y administrativos, el caso brasileño ha demostrado la importancia de la redefinición del orden jurídico, para que sean creadas las bases de un marco regulatorio de gobernanza del acceso al suelo urbano y a la vivienda que sea incluyente, y en el cual nuevos principios y conceptos jurídicos (especialmente el reconocimiento de derechos colectivos), mecanismos institucionales y procesos sociopolíticos sean articulados con propiedad. La perspectiva de la reforma urbana también requiere acceso más amplio al poder judicial para ayudar a hacer avanzar las fronteras jurídicas desde dentro del sistema jurídico, así como para garantizar la eficacia de la legislación en vigor.

Sin embargo, este es un proceso de fuertes y renovadas disputas políticas, y cambiar las reglas del juego - por más difícil que eso sea- no es garantía de que el juego va a ser jugado de acuerdo con las nuevas reglas. En verdad, la aprobación de leyes progresistas puede perversamente contribuir a la creación de un discurso jurídico y de una práctica político-institucional que afecten la movilización de la sociedad civil, manteniendo así sin cambio -si no también legitimando- las principales fundaciones del statu quo excluyente. Ya hay toda una literatura creciente sobre las posibilidades, límites y contradicciones intrínsecas de los procesos participativos, especialmente los presupuestos participativos y planes maestros municipales.

También por esa razón, la materialización de las posibilidades de cualquier sistema jurídico redefinido -y su traducción en un nuevo pacto sociopolítico- depende de cómo puede ser jurídica y políticamente apropiado por los grupos interesados. IEURE 


\section{Referencias bibliográficas}

De Souza, M. L. (2001). The Brazilian way of conquering the 'right to the city': successes and obstacles in the long stride towards an 'urban reform'. DISP Vol. 147.

Fernandes, E. (1992a). Law, politics and environmental protection in Brazil. Journal of Environmental Law Vol. 4, No 1.

Fernandes, E. (1992b). Juridical-institutional aspects of metropolitan administration in Brazil. Third World Planning Review Vol. 14, No 3.

Fernandes, E. (1993). The legal regularization of favelas in Brazil. The case of Belo Horizonte. Social and Legal Studies Vol. 2.

Fernandes, E. (1994). Defending collective interests in Brazilian environmental law: an assessment of the civil public action. Review of European Community and International Environmental Law Vol. 3, No 4.

Fernandes, E. (1995a). Curitiba, Brazil: successfully integrating land use and transport policies. International Report Vol. 5.

Fernandes, E. (1995b). Collective interests in Brazilian environmental law. En D. Robinson \& J. Dunkley (Eds.). Public Interest Perspectives in Environmental Law. Chichester: Wiley Chancery Law.

Fernandes, E. (1995c). Law and Urban Change in Brazil. Aldershot: Avebury.

Fernandes, E. (1995d), Participatory budget: a new experience of democratic administration in Belo Horizonte, Brazil. International Report, Issue 11.

Fernandes, E. (1996). Constitutional environmental rights in Brazil. En M. R. Anderson \& A. E. Boyle (Eds.). Human Rights Approaches to Environmental Protection. Oxford: Oxford University Press.

Fernandes, E. (2000). The legal regularization of favelas in Brazil: problems and prospects. Third World Planning Review Vol. 22, No 2.

Fernandes, E. (2002a). Providing security of tenure for the urban poor: the Brazilian experience. En A. Durand-Lasserve \& L. Royston (Eds.). Holding their Ground - Secure Land Tenure for the Urban Poor in Developing Countries. London: Earthscan.

Fernandes, E. (2002b). Combining tenure policies, urban planning and city management in Brazil. En G. Payne (Ed.). Land, Rights and Innovation - Improving Tenure Security for the Urban Poor. London: ITDG.

Fernandes, E. (2003). Del Código CiviI al Estatuto de la Ciudad: algunas notas sobre la trayectoria del Derecho Urbanístico en Brasil. EURE Vol. 29.

Fernandes, E. (2006). Principles, bases and challenges of the national programme to support sustainable urban land regularization in Brazil. En M. Huchzermeyer \& A. Karam (Eds.). Informal Settlements - A Perpetual Challenge? Cape Town: University of Cape Town Press.

Fernandes, E. \& Rolnik, R. (1998). Law and urban change in Brazil. En E. Fernandes \& A. Varley (Eds.). Illegal Cities - Law and Urban Change in Developing Countries. London: Zed Books.

Fernandes, E. \& Valença, M. (Eds.) (2001). Urban Brazil: past and future. Geoforum Vol. 32, No 4, Special Issue, Elsevier, London.

Kowarick, L. (Ed.) (1994). Social Struggles and the City. The Case of São Paulo. New York: Monthly Review Press.

Souza, C. (2001). Participatory budgeting in Brazilian cities: limits and possibilities in building democratic institutions. Environment \& Urbanization Vol. 13, No 1. 